IRA-International Journal of Management \&

Social Sciences

ISSN 2455-2267; Vol.15, Issue 01 (April, 2019)

Pg. no. 1-6.

Institute of Research Advances

http://research-advances.org/index.php/RAJMSS

\title{
Convergence or Divergence Among Indian States: A Study Of New Series Data
}

\section{Dr A. Vamsi Krushna}

Assistant Professor, Dept. of Humanities and Social Sciences, GITAM School of Gandhian Studies, GITAM Deemed to be University, Visakhapatnam, A.P, INDIA.

Type of Work: Peer Reviewed.

DOl: http://dx.doi.org/10.21013/jmss.v15.n1.p1

\section{How to cite this paper:}

Krushna, A.V. (2019). Convergence or Divergence Among Indian States: A Study Of New Series Data. IRA-International Journal of Management \& Social Sciences (ISSN 2455-2267), 15(1), 1-6. doi:http://dx.doi.org/10.21013/jmss.v15.n1.p1

(C) Institute of Research Advances.

\section{(oc) EY-NC}

This work is licensed under a Creative Commons Attribution-Non Commercial 4.0 International License subject to a proper citation to the publication source of the work.

Disclaimer: The scholarly papers as reviewed and published by the Institute of Research Advances (IRA) are the views and opinions of their respective authors and are not the views or opinions of the IRA. The IRA disclaims of any harm or loss caused due to the published content to any party.

Institute of Research Advances is an institutional publisher member of Publishers International Linking Association Inc. (PILA-CrossRef), USA. The institute is an institutional signatory to the Budapest Open Access Initiative, Hungary advocating the open access of scientific and scholarly knowledge. The Institute is a registered content provider under Open Access Initiative Protocol for Metadata Harvesting (OAI-PMH).

The journal is indexed \& included in WorldCat Discovery Service (USA), CrossRef Metadata Search (USA), WorldCat (USA), OCLC (USA), Open J-Gate (India), EZB (Germany) Scilit (Switzerland), Airiti (China), Bielefeld Academic Search Engine (BASE) of Bielefeld University, Germany, PKP Index of Simon Fraser University, Canada. 


\begin{abstract}
Till now there is a vast literature available on this subject both theoretically and empirically. All the studies are mostly observing this convergence/divergence nature over a long period of time. To quote some of the researches such as Trivedi (2002), Bandyopadhyay (2002), Michelle, Kirsty and Cassen (2005), Nayyar (2008), Kalra \& Sodsriwiboon (2010), Ghosh (2012), Stewart and Moslares (2014), Mishra and Mishra (2017) and Chakraborty and Chakraborty (2018) all are considered long period of time to estimate the presence of convergence/divergence among Indian states. But the long term development of a region depends upon so many factors such as availability of natural resources, human resources, economic policies adopted in the region, political climate etc. Hence, when we are dealing with the issue of convergenceldivergence we have to consider the above-said factors. From this point of view, this paper focuses on the short term observing of convergence/divergence particularly with reference to Indian states during the period 2011-12 to 2016-17. High Growth Group States witnessed convergence in PCNSDP while Low Growth Group States and the Total States exhibited divergent trends. The high Growth Group States converged at a rate of 49.8 per cent during the study period. The rate of divergence among the Low Growth Group States is 14.5 per cent. Regarding the Total States, the rate of divergence is observed as 12.4 per cent. Here also the high growth group states are accounted for fewer fluctuations when compared with low growth group states.
\end{abstract}

Keywords: $\sigma$-Convergence, Coefficient of Variation, Indian states

\title{
Introduction
}

In any economy, regional divergences are inevitable in various dimensions. These divergences can be measured in terms of income, education, health and various parameters. Obviously, nationally or internationally the major focus is on the income dimension to address the regional inequalities. Whenever we are comparing different regions of a nation this income dimension is captured through per capita income of a region. During the course of time, the increase in per capita income of all regions are compared and claimed that some regions are developed whereas some are underdeveloped. These are compared overtime by referring to their income growth. To put it empirically the economists estimated the income growth of an economy and based on that the regions are grouped as higher as or lower than the average growth of the economy. Then we are interested to observe whether the lower group is able to reach the level of a higher group or not considering the time period. This is what we call it "convergence/divergence" of different regions of a country.

Till now there is a vast literature available on this subject both theoretically and empirically. All the studies are mostly observing this convergence/divergence nature over a long period of time. To quote some of the researches such as Trivedi (2002), Bandyopadhyay (2002), Michelle, Kirsty and Cassen (2005), Nayyar (2008), Sanjay\& Sodsriwiboon (2010), Ghosh (2012), Stewart and Moslares (2014), Mishra and Mishra (2017) and Chakraborty and Chakraborty (2018) all are considered long period of time to estimate the presence of convergence/divergence among Indian states. But the long term development of a region depends upon so many factors such as availability of natural resources, human resources, economic policies adopted in the region, political climate etc. Hence, when we are dealing with the issue of convergence/divergence we have to consider the abovesaid factors. From this point of view, this paper focuses on the short term observing of convergence/divergence particularly with reference to Indian states during the period 2011-12 to 2016-17.

\section{Review of Literature}

Trivedi,(2002) examined the evidence for regional convergence or catch-up in levels and growth rates of per capita income among the 16 major states in India between 1960 and 1992 . He observed that there is no evidence of unconditional $\beta$-convergence but found the existence of conditional $\beta$-convergence and divergence.

Bandyopadhyay (2002) examined the convergence of growth and incomes with reference to the Indian states using an empirical model of dynamically evolving distributions. His model revealed "twin peaks" dynamics or polarization across the Indian states, over 1965-1997. 
Michelle, Kirsty and Cassen (2005) analysed India's regional disparities in economic performance between 1970-1997. Their econometric analysis presented weak evidence for conditional convergence. They also highlighted that economic policy reforms in 1991 significantly intensified growth differentials between the states.

Nayyar (2008) analysed whether or not states in India, at disparate levels of income and development, exhibit any tendency in the data to converge to common steady-state paths among 16 major Indian states for the period 1978-79 to 2002-03. He observed that there is no evidence of absolute $\beta$-convergence and $\sigma$ - convergence but noticed the presence of conditional $\beta$-convergence.

Sanjay\& Sodsriwiboon (2010) also examined the convergence and spillovers across Indian states utilizing non-stationary panel data techniques. Their study found evidence of divergence for the period from 1960 to 2003. However, convergence was found for the sub-period related to structural breaks. Further, they also examined club convergence and they found strong evidence of club convergence among the high-income and low-income states.

Ghosh (2012) examined the economic convergence of 15 major states in India during the period 1960-612006-07. He observed that in the post-reform period the states have diverged in per capita income.

Stewart and Moslares (2014) analysed the convergence of 16 states during the period 1980-2010. They confirmed that the poorest states did not grow faster than the richest states ( $\beta$ - convergence) and that the cross-state dispersion of income levels did not decrease throughout the observation period ( $\sigma$-convergence).

Mishra and Mishra (2018) analysed the conditional income convergence hypothesis for 17 major states in India for the period of 1960-2012 using univariate stationarity tests. Their findings of stationarity tests without structural breaks confirm the convergence hypothesis. However, when multiple structural breaks are incorporated in unit root tests in per capita income series, the incomes of only around 11-13 states are found to stochastically converge to the national average, supporting the convergence hypothesis.

Chakraborty and Chakraborty (2018) observed convergence among 28 Indian states during the period 2001-14 and found divergence nature.

\section{Data and Methodology}

The data on Per Capita Net State Domestic Product (PCNSDP) is taken for 21 states of India from the Handbook of Statistics on Indian Economy, 2017 published by RBI. Then the selected 21 states are grouped into high and low growth group states based on the All India PCNSDP in the year 2016-17. If a state has more than all India PCNSDP it is placed in a high growth group otherwise in a low growth group.

As per the latest the base year 2011-12, the all-India PCNSDP is Rs. 82229 in 2016-17. The states which have higher than all-India PCNSDP is 12 states and the remaining 9 states are having lower than all-India PCNSDP. The grouping of states into high and low growth states is presented in Table-1.

Table-1: State Groups

\begin{tabular}{|l|l|}
\hline $\begin{array}{l}\text { High Growth Groups } \\
\text { States (12) }\end{array}$ & $\begin{array}{l}\text { Andhra Pradesh, Goa, Gujarat, Haryana, Himachal Pradesh, } \\
\text { Karnataka, Kerala, Maharashtra, Punjab, Tamil Nadu, } \\
\text { Telangana, } \\
\text { Uttarakhand }\end{array}$ \\
\hline $\begin{array}{l}\text { Low Growth States } \\
\text { (09) }\end{array}$ & $\begin{array}{l}\text { Bihar, Chhattisgarh, Jammu \& Kashmir, Jharkhand, Madhya } \\
\text { Pradesh, Odisha, Rajasthan, Uttar Pradesh, West Bengal }\end{array}$ \\
\hline Source: Author's calculation based on the Handbook of Statistics on Indian \\
Economy, RBI, 2017
\end{tabular}

To observe the presence or absence of $\sigma$-convergence, the Coefficient of Variation (CV) is regressed on time for both high and low growth group states and also for total states. A CV is a standard measure to analyse the inequalities between or among different groups. The group which shows less CV is to be considered as more 
consistent and vice versa. The $\mathrm{CV}$ is calculated as the ratio of standard deviation to mean. If this ratio is multiplied by 100 then we have $\mathrm{CV}$ in percentage terms.

The formula for calculating $\mathrm{CV}$ is as follows:

$$
\text { Coefficient of Variation }(\mathrm{CV})=\frac{\text { Standard Deviation }(\mathrm{SD})}{\text { Mean }} \times 100
$$

To examine the $\sigma$ - Convergence presence or absence regression technique has been deployed. The functional form of the equation is:

$$
\mathrm{Y}_{\mathrm{i}}=\alpha+\beta \mathrm{X}_{\mathrm{i}}+\mathrm{u}_{\mathrm{i}}
$$

Where $\mathrm{Y}_{\mathrm{i}}=$ Dependent Variable

$$
\begin{aligned}
& \alpha=\text { Intercept of the regression equation } \\
& \beta=\text { Slope of the regression equation } \\
& \mathrm{X}_{\mathrm{i}}=\text { Independent Variable } \\
& \mathrm{u}_{\mathrm{i}}=\text { Error term of the regression equation which distributes normally and }
\end{aligned}
$$

Here, the CV of PCNSDP are taken as dependent variable $\left(\mathrm{Y}_{\mathrm{i}}\right)$. Time is considered as an independent variable $\left(\mathrm{X}_{\mathrm{i}}\right)$. The negative sign of the beta coefficient indicates the presence of $\sigma$ - Convergence and vice versa. To obtain the regression results SPSS 20 version software is used.

\section{Results}

\section{Coefficient of Variation}

Coefficient of Variation for high and low growth group states and for the total states is presented in Table-2 and in Graph-1. From the Table-2, it can be observed that high growth group states and total states are moving in the same direction i.e., for these both groups respective CV has declined from 2011-12 to 2013-14 and from 2013-14 onwards it has witnessed an increasing trend. In the case of low growth, group states the CV is almost stagnant during the study period. This is clearly visible in the Graph-1.

Table-2: CV Analysis Results

\begin{tabular}{|c|r|r|r|}
\hline Year & \multicolumn{1}{|c|}{$\begin{array}{c}\text { CV of } \\
\text { High Group } \\
\text { PCNSDP }\end{array}$} & $\begin{array}{c}\text { CV of } \\
\text { Low Group } \\
\text { PCNSDP }\end{array}$ & $\begin{array}{c}\text { CV of } \\
\text { Total States } \\
\text { PCNSDP }\end{array}$ \\
\hline $2011-12$ & 44.7299 & 25.32236 & 61.24095 \\
\hline $2012-13$ & 33.6405 & 24.67075 & 52.32171 \\
\hline $2013-14$ & 24.39921 & 25.59561 & 46.17057 \\
\hline $2014-15$ & 32.81856 & 25.18911 & 53.31901 \\
\hline $2015-16$ & 36.19084 & 26.11454 & 56.72109 \\
\hline $2016-17$ & 38.03009 & 25.54889 & 58.03793 \\
\hline
\end{tabular}

Source: Author's calculation based on the Handbook of Statistics on Indian Economy, RBI, 2017 


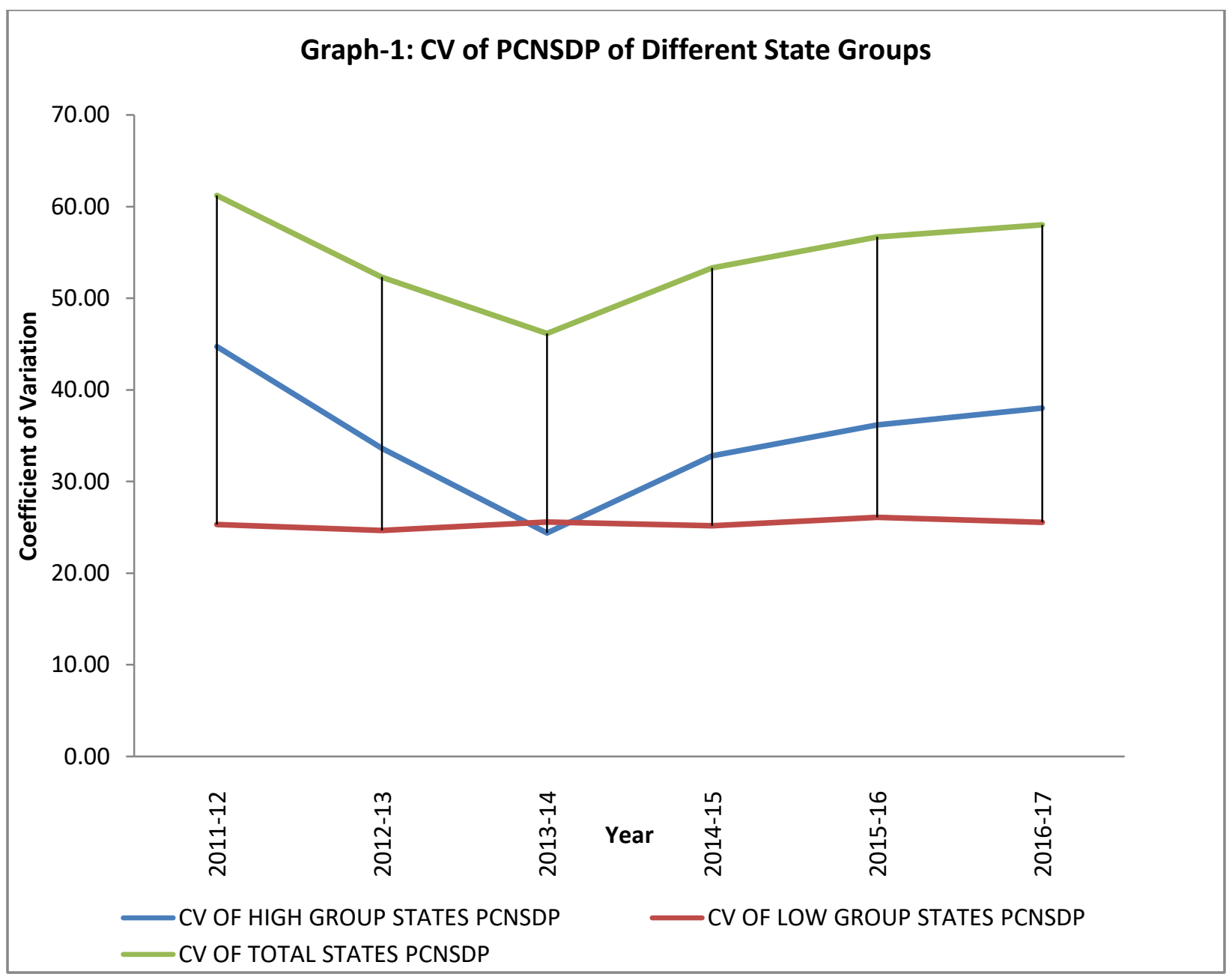

\section{$\sigma$ - Convergence}

$\sigma$ - convergence test is performed to assess whether the Indian States are converged or diverged in PCNSDP during the period 2011-12 to 2016-17. The results are shown separately for each sector and for each group of states and for combined states.

High Growth Group States witnessed convergence in PCNSDP while Low Growth Group States and the Total States exhibited divergent trends. The coefficients of High Growth Group, Low Growth Group and the Total States are statistically not significant. Only 1.9 percentage of variation of CV in PCNSDP has been explained by $\mathrm{R}^{2}$ for High Growth Group States and for the Low Growth Group States 31.7 percentage of variation. For the Total States, a meagre 0.2 percentage of variation of CV in PCNSDP has been explained by $\mathrm{R}^{2}$. This clearly shows that there are some other variables which have more influence than the time during the study period to cause changes in the CV of PCNSDP for both high and low growth group states and for total states. The high Growth Group States converged at a rate of 49.8 per cent during the study period. The rate of divergence among the Low Growth Group States is 14.5 per cent. Regarding the Total States, the rate of divergence is observed as 12.4 per cent. Here also the high growth group states are accounted for fewer fluctuations when compared with low growth group states. 
IRA-International Journal of Management E̊ Social Sciences

Table-3: $\sigma$ - Convergence Test Results

\begin{tabular}{|c|c|c|c|c|c|c|c|c|}
\hline Model & \multicolumn{8}{|c|}{$\left(C V\right.$ PCNSDP) $Y=\beta_{0}+\beta_{1}(t)$} \\
\hline Parameters & $\beta_{0}$ & $\mathrm{t}\left(\beta_{0}\right)$ & Sig t $\left(\beta_{0}\right)$ & $\beta_{1}$ & $\mathrm{t}\left(\beta_{1}\right)$ & $\operatorname{Sig} t\left(\beta_{1}\right)$ & $\mathrm{R}^{2}$ & $\mathrm{~F}$ \\
\hline $\begin{array}{l}\text { High Growth Group } \\
\text { States }\end{array}$ & 1037.616 & .291 & .786 & -.498 & -.281 & .793 & .019 & .079 \\
\hline $\begin{array}{l}\text { Low Growth Group } \\
\text { States }\end{array}$ & -265.544 & -1.243 & .282 & .145 & 1.362 & .245 & .317 & 1.856 \\
\hline Total States & -194.550 & -.069 & .948 & .124 & .088 & .934 & .002 & .008 \\
\hline
\end{tabular}

\section{Conclusion}

The literature on convergence majorly focused on long term observation of the presence or absence of convergence/divergence and it reveals the different picture at different times under consideration of the study. Often we do not find the same exercise for a short period of time. So this study tries to observe convergence/divergence among Indian states during the short period of time 2011-12 to 2016-17. High Growth Group States witnessed convergence in PCNSDP while Low Growth Group States and the Total States exhibited divergent trends. The high Growth Group States converged at a rate of 49.8 per cent during the study period. The rate of divergence among the Low Growth Group States is 14.5 per cent. Regarding the Total States, the rate of divergence is observed as 12.4 per cent. Here also the high growth group states are accounted for fewer fluctuations when compared with low growth group states.

\section{References}

[1]. Gaurav Nayyar. (2008). Economic Growth and Regional Inequality in India, Economic and Political Weekly, XLIII(6), 58-67.

[2]. Ghosh, Madhusudan. (2012). Regional Economic Growth and Inequality in India during the Pre- and Post-reform Periods, Oxford Development Studies, 40(2), 190-212.

[3]. Lekha Chakraborty \& Pinaki Chakraborty. (2018). Federalism, Fiscal Asymmetries and Economic Convergence: Evidence from the Indian States. NIPFP Working Paper No. 232.

[4]. Michelle, B., Kirsty, M., \& Robert, C. (2007). Divergence in India: Income differentials at the state level, 197097. The Journal of Development Studies, 42(6), 1000-1022.

[5]. Mishra, Ankita \& Vinod Mishra. (2017). Re-examination of convergence hypothesis among Indian states in panel stationarity testing framework with structural breaks, Applied Economics, 50 (3), 268-286.

[6]. Ross Stewart, \& Carlos Moslares. (2014). Regional Disparities Across Indian States: Are the Trends Reversing? Journal of Economics and Development Studies, 2 (3), 95-111.

[7]. Sanghamitra, B. (2002). Twin Peaks: Distribution Dynamics of Economic Growth across the Indian States, Retrieved from https://editorialexpress.com/cgi-bin/conference/download.cgi?dbname=NASM2002\& paper $\mathrm{id}=301$

[8]. Sanjay, K., \& Sodsriwiboon, P. (2010). Growth Convergence and Spillovers among the Indian States: What Matters? What Does Not?. IMF Working Paper, WP/10/96.

[9]. Trivedi, K. (2002). Regional Convergence and Catch-up in India between 1960 and 1992. Mimeo, Oxford University. Retrieved from http://www.nuff.ox.ac.uk/economics/papers/2003/w1/convergencewp1.pdf 